\title{
EVALUATION OF THE NUTRITION EFFECTIVENESS OF THE MILITARY PERSONNEL OF THE BULGARIAN ARMY DURING THE PREPARATION FOR PARTICIPATION IN EXPEDITIONARY OPERATIONS
}

\author{
Nikolay NICHEV \\ "Vasil Levski” National Military University, Veliko Tarnovo, Bulgaria \\ nbnichev@nvu.bg
}

\begin{abstract}
The conditions of a resource deficit and the new security environment predetermine the transformation of the logistics system in the Bulgarian Army as one of the most serious challenges facing the adaptation of the Armed Forces of Republic of Bulgaria to the requirements of the modern expeditionary operations. The problems, connected with the organization of the nutrition of the military personnel from the Ministry of Defense and the Bulgarian Army is a process, which is consistent with the contemporary requirements in the sphere of healthy nutrition and food safety, with the European guidelines and recommendations and with the experience of the Bulgarian scientists gained during a long period in this sphere. In result of the given circumstances emerged an unbalance between resources and abilities. This fact together with the challenges of the integrated logistics, require with an increasing keenness the systematic development of defensive abilities of the armed forces of our country and of the military units, participating in expeditionary operations. This development must have balanced abilities, covering all the components for the performance of the full spectrum of tasks, provoked by the expected scenarios and analyses for the development of the military strategy for security, based on a manager's approach for the expenditure of defensive resources for the logistic supply with food of the units abroad.
\end{abstract}

KEYWORDS: nutrition, expeditionary operations

\section{Introduction}

The conditions of a resource deficit and the new security environment predetermine the transformation of the logistics system in the Bulgarian Army as one of the most serious challenges facing the adaptation of the Armed Forces of Republic of Bulgaria to the requirements of the modern expeditionary operations.
With the development plan of the Armed Forces of Republic of Bulgaria until 2020 a requirement is laid down to the kind of armed forces to keep themselves in a preparedness and to participate with military units in international operations in respond to crises outside the territory of the country, performing the mission "Support of the world peace and security". 
These operations are more frequently carried out in an insecure environment of threat to the units, exposed to specific physical and mental loads. In this context a significant condition for the maintenance of the health of the military personnel from the units, not only during their preparation for expeditionary operations, but also in the areas of these operations, is the timely provision supply, according to the nutrition standards.

The problems, connected with the organization of the nutrition of the military personnel from the Ministry of Defense and the Bulgarian Army is a process, which is consistent with the contemporary requirements in the sphere of healthy nutrition and food safety, with the European guidelines and recommendations and with the experience of the Bulgarian scientists gained during a long period in this sphere.

In result of the given circumstances emerged an unbalance between resources and abilities. This fact together with the challenges of the integrated logistics, require with an increasing keenness the systematic development of defensive abilities of the armed forces of our country and of the military units, participating in expeditionary operations. This, in itself, involves and requires the implementation of contemporary scientific approaches to the development of armed forces (Nichev, 2017a). This development must have balanced abilities, covering all the components for the performance of the full spectrum of tasks, provoked by the expected scenarios and analyses for the development of the military strategy for security, based on a manager's approach for the expenditure of defensive resources for the logistic supply with food of the units abroad.

\section{Explanation}

In number of researches P. Glushkov (2017a) suggests new nutritional standards. They are grounded on a selection of foodstuffs within the weekly menu of the servicemen during preparation for participation in expeditionary operations. The contents of the newly elaborated selection of foodstuffs, is consistent with the food groups classification, suggested by the National recommendations for healthy nutrition of the population. It comprises: cereals and potatoes; vegetables and fruit; milk and dairy products; meat, fish, leguminous and nuts; added fats (butter, fat, sunflower oil, maize oil, olive oil, margarine and others); sugar and sugar products, sweets. For the determination of foodstuffs selection, P. Glushkov (2017b) adopts the approach of exclusion or reduction to the smallest possible amount of non-healthy foods. It comes to the following foodstuffs groups: foods with contents of partially hydrogenated plants oil; specific foods with high contents of salt; specific foods and beverages containing caffeine or taurine; specific foods or beverages with high contents of sugars and sweeteners.

The quantity of foodstuffs in the recommended new standards for preparation of food for the servicemen during the preparation for participation in expeditionary operations gives the opportunity to make up a balanced and rational menu.

According to some authors in the theory and practice of management of the companies, the effectiveness is considered to be a fundamental economic category (Terziev \& Nichev 2016; Nichev, 2017b). It reflects the causal relationships in a quantity and quality aspect between the results and the expenses needed for obtaining them. Depending on the essence and the contents of the results and the expenditures, the effectiveness, in the aspect of nutrition of special contingents of the population, exposed to specific physical and mental loads during the direct preparation for participation in expeditionary operations, can be examined 
in the context of the socio-economic, planned and factual effectiveness (Nichev \& Glushkov, 2016).

Prof. Banabakova (2010) examines the quantity and quality common and partial indicators for measuring the effectiveness of the logistics activities. According to her, the most effective logistics activities are those, which subordinate the separate work procedures to the general logistics strategy, which, in its turn ought to be in conformity with the organization strategy. The purposes of the organization strategy build the basis for the determination of the level of effectiveness, needed for the achievement of success and the opportunities for the most precise measuring of this effectiveness. This approach requires from us to examine the logistics as basic strategy means, not a function, evoking expenses, also the necessity of a complete coordination between the logistics activities and the marketing, the production, the sales, the researches and the other operational functions of the organization. In order the logistics to perform its purpose, it's advisable to work out such a system of indicators for the evaluation of its effectiveness, which could control the performance of the logistics activities in pursuit of responding to the strategic purposes of the organization. If at a particular moment the logistics wouldn't develop in direction of achieving the strategic aims, it would be necessary to undertake the suitable corrective actions.

The development of a system of indicators for measuring of the effectiveness of the logistics system demands an analysis of the performance of the organization, and in particular of the logistic purposes and of the degree of satisfaction of the consumers about the offered logistics service. The criteria for effectiveness of the logistic actions ought to be adapted to the changes in the macro- and microeconomic environment.
Depending on the aims of the evaluation of the effectiveness, the following basic effects can be perceived: profit, incomes, volume of the logistic activity, reduction of the expenditures on logistic and others.

In case of a profit effect, the effectiveness can be measured as a relation of the profit to the sum of the capital and the aggregate expenses on logistic activities. Calculated this way, the effectiveness shows how much levs from the profit correspond to one or one hundred levs of the aggregate expenses on logistic activities - advance value and running expenses. The formula can be developed further if the capital is depicted as a sum total of the separate kinds of capital, invested for logistics, while the expenses as a sum total of the separate groups or sorts of expenses on logistic activities.

The measuring of the effectiveness, by means of the indicator for a profit effect reflects to the highest extent the economic changes for the implementation of the logistic activities. This is an indicator, which binds most precisely and expresses what the final result would be obtained from the implementation of the logistic activities, moreover not in the form of a sum total, but for each unit or for one hundred levs of the spent aggregate expenditures on logistics. This means of measuring of the effectiveness shows, that each ungrounded increase of the expenses or each unconsidered implementation of the capital reflects immediately negative on the effectiveness. The determination of the effectiveness of the logistical activities, by means of profit, can be implemented generally or for each single logistical activity. In all cases the general changes of the effectiveness of the logistic system, are predetermined by the changes of these indicators for the single logistic activities, because in each logistic activity there are available specific conditions for formation of the profit, also for determination of the 
extent of implementation of the advance capital and for the taken expenditures on logistic.

In case of an income effect, the effectiveness can be measured as a relation of the incomes to the sum total of the capital and the aggregate expenses on logistic activities. The more detailed analysis requires the effectiveness to be measured based on the individual kinds of incomes - according to the groups and kinds and by means of the different displays of the capital and groups or the sorts of expenditures for the separate logistic activities. This way, during the analysis process, it's possible to reflect the quantity influence of each group of incomes or of expenses for logistic activities and the capital on the changes of the effectiveness. It's advisable, to represent the incomes, the expenses and the capital according to the sorts of logistic activities, in result of which, to determine the importance of each logistic activity for the development of the effectiveness of the logistic system, expressed by means of the incomes.

In case of an "activity volume" effect, the effectiveness can be measured, putting in the numerator the aggregate economic turnover, while in the denominator - the total sum of the capital and of the expenses on logistic activities. The economic turnover can represent for the separate activities the volume of the separate logistic activities (supply, transport, warehousing, logistic servicing, maintenance and others). In determination of the total effectiveness of the logistic activities, the volume, represented in the numerator, can be expressed through the total sum of the volumes of the individual logistic activities. It can be done the same way with the capital and the expenses on logistics.

In case of a "reduction of expenses" effect, the effectiveness ought to be measured the following way: in the denominator should be represented the difference between the expenses for logistic activities during the current period and the expenses on logistic activities for the past period or as planned, while in the numerator - the total sum of the capital and the aggregate expenses on logistic activities. The indicator "reduction of expenses" can be used for measuring of the effectiveness of the logistic system, mainly when investments in new technique and technologies have been made.

The effectiveness of the suggested new standards for nutrition can be determined and evaluated according to the following indicators:

$>$ Effective implementation of the food costs, spent by the Ministry of Defense - social effectiveness;

Effectiveness of nutrition - factual effectiveness.

According to the first indicator the effective implementation of the costs for food, spent by the Ministry of Defense social effectiveness, its determination is possible by means of the following approach, when the evaluation according to this indicator is linked with the determination of the cost of $1 \mathrm{kcal}$, which is planned to be granted based on the new nutrition norms and the cost of $1 \mathrm{kcal}$ according to the current nutrition norms. Then it's necessary to calculate what quantity of energy (kcal) would be possible to insure for the consumers of the food according to the current nutrition norms in case, that norms proceed to be valid, related to the value of $1 \mathrm{kcal}$, planned to be granted, according to the new standards. Finally, it's necessary to consider the values of energy, which must be obtained in case of the both variants of action - if the norms weren't corrected and if the norms were corrected by new ones.

The calculation of the average cost of $1 \mathrm{kcal} /$ daily for a particular time period, during which specific nutrition norms are valid, can be calculated using the following formula: 


$$
C_{\text {kcal /daily }}=\frac{P_{\text {cost } t \text { daily }}}{P l_{\text {kcal /daily }}},
$$

where:

$\mathrm{C}_{\mathrm{kcal} / \mathrm{daily}}$ - average cost for $1 \mathrm{kcal} /$ daily, in levs;

$\mathrm{P}$ cost/daily - maximal amount of financial resources for the preparation of food for one person per day, according to the valid enactment of the Bulgarian Army, [levs];

Pl kcal/daily - planned daily average quantity of calories during the period, [kcal].

In our case the examined periods are the present period, when the military nutrition norms are valid and the future period, when it would be possible, that the suggested new nutrition standards are adopted. According to the present valid norms for the persons, preparing for participation in expeditionary operations, energy of 4560 kilocalories per day at the cost of 9.50 levs is insured. The suggested new nutrition norms foresee to insure 3532 kilocalories per day at the cost 8.02 levs. After calculating by means of formula (1.), we obtain the following results:

$>$ For the present period $-\mathrm{C}_{1} \mathrm{kcal} / \mathrm{daily}$ $=0.002083333$ levs;

For the future period $-\mathrm{C}_{2}$ kcal/daily $=0.002270668$ levs.

For the calculation of the energy quantity (kcal), which can be insured to the consumers, according to the current nutrition norms, related to the cost of 1 kcal, which is planned to be insured, according to the new nutrition norms, the following formula can be used:

$$
K_{\text {Erelated/dail }}=\frac{P_{\cos t / d a i l y}}{C_{2 k c a l / d a i l y}},
$$

where:

$\mathrm{K}$ E related/daily - quantity of energy, which could be insured to the consumers, according to the current nutrition norms, in case they have continued to be valid, related to related to the cost of $1 \mathrm{kcal}$, which is planned to be insured, according to the new nutrition norms, [kcal];

$\mathrm{C}_{2}$ ккал/ден - average cost for $1 \mathrm{kcal}$, [levs/ kcal];

$\mathrm{P}$ cost/daily - maximal amount of the financial resources for preparation of food for one person per day, according to the valid enactment of the Bulgarian Army, [levs].

After calculating by means of formula (2), we obtain the following result:

$$
\mathrm{K}_{\text {E related/daily }}=4184 \mathrm{kcal} \text {. }
$$

This result shows us on one hand, that if we continue applying the current nutrition standards, without the slightest correction based on the present/prognostic results, the entitled persons would receive food with energy value $8.2 \%$ less than the present. On the other hand, the value of $\mathrm{K}_{\mathrm{E}}$ related/daily gives us the ground to affirm, that the consumers will receive food with 14 $18 \%$ smaller energy value in case, that we bring into use the new nutrition norms. This situation appears to be unacceptable, because the energy value of the food would not correspond to the scientifically proved physiological nutrition standards. In this case we could not assert that the implementation of the resources for nutrition, spent by the Ministry of Defense, is effective. A social effectiveness couldn't be achieved, because the unbalance of the energy need creates preconditions for the increase of the risk to the health of the consumers. Finally, it's necessary to assess the energy values, which ought to be achieved in both variants of action - in case of correction or without correction of the present standards.

In case of the variant of action without correction of the norms, the following formula can be used:

$$
E_{c e}=\frac{N_{a v L R k c a l / d a i l y}}{K_{\text {Erelated/daily }}},
$$


where:

$\mathrm{E}_{\mathrm{ce}}-$ Social effectiveness, [\%];

$\mathrm{K}$ Erelated/daily - energy quantity, which could be insured to the consumers, according the present nutrition norms, related to the cost of $1 \mathrm{kcal}$, planned to be granted based on the new nutrition norms, [kcal];

$\mathrm{N}_{\mathrm{av}}$ LR kcal/daily - Average energy needs, according to the linear restrictions, [kcal]. $=3516 \mathrm{kcal}$.

In case of the variant of action - the norms are corrected with new ones, the following formula can be used:

$$
E_{c e}=\frac{N_{\text {avLRkcal/daily }}}{K_{\text {Eom/daily }}},
$$

where:

$\mathrm{E}_{\text {ce }}-$ Social effectiveness, [\%];

K E ом/daily - Decision of the optimization model about the quantity of energy, which must be insured to the consumers, according the new nutrition norms, [kcal];

$\mathrm{N}_{\text {av }}$ LR kcal/daily - Average energy needs, according to the linear restrictions, [kcal]. $=3516 \mathrm{kcal}$.

The decisions for both decisions can be determined as socially effective in case that they are within the limits: $\geq 0,977$ and $\leq 1,024 \quad\left(\frac{3432_{k c a l}}{3516_{k c a l}}\right.$ and $\left.\frac{3600_{k c a l}}{3516_{k c a l}}\right)$.

After calculating by means of formulas (4) and (5) the following result is obtained:

$>$ For variant of action - without correction of the norms $\mathrm{E}_{\mathrm{ce}}=0.840$.

$>$ For variant of action - with correction of the norms with new ones $\mathrm{E}_{\mathrm{ce}}=0.995$.

According to the set limits, which determine the nutrition norms (including present and new ones) as socially effective or not, solely under the second variant of action, when the norms are corrected, it can be indicated, that a social effectiveness is achieved.
It's possible while performing the inspection and correction of the nutrition norms at short intervals of time, while evaluating the costs of the energy, which ought to be obtained under both variants of action, to obtain such result for both variants, which satisfy the limits of the social effectiveness. For example, such possible situation is available, when from the moment of implementation of the corrected nutrition norms until the time of undertaking an inspection and a possible correction, no significant changes take place, such as: national physiological nutrition norms or other scientifically grounded norms, which are used; the prices of the foodstuffs; the food preference of the examined group.

According to the second indicator nutrition effectiveness, the factual effectiveness ought to be calculated. For this purpose the following formula can be used

$$
E_{f e n m(w)}=\frac{P_{\cos t / d a i l y}}{C_{e n m(w) / d a i l y}},
$$

where:

$\mathrm{E}$ fen $\mathrm{m}-$ Factual effectiveness of nutrition for men, [\%];

$\mathrm{E}$ fen w - Factual effectiveness of nutrition for women, [\%];

$\mathrm{P}_{\text {cost/daily }}$ - The maximal amount of the financial resources for preparation of food for one person per day, according to the valid enactment of the Bulgarian Army, [levs];

$\mathrm{C}_{\text {enm/daily }}-$ Cost of the energy need for men per day, [levs];

$\mathrm{C}$ enw/daily - Cost of the energy need for women per day, [levs].

In our case the maximal amount of the financial resources for preparation of food for one person per day, according to the valid enactment of the Bulgarian Army is 9.50 levs. The cost of the energy need for military and civilian personnel (men) during a national preparation for 
participation in expeditionary operations, evaluated in levs, according to the decision of the linear optimization model and the suggested new nutrition norms, is 8.02 levs. After the done calculation with formula (6) the following result is obtained:

$$
\mathrm{E}_{\mathrm{fn}}=118 \%
$$

The result demonstrates a higher effectiveness out of the point of view of the energy contents, by implementation of the suggested new nutrition norms.

\section{Conclusion}

The results of the measuring according to the above listed two indicators, concerning the suggested new nutrition norms, demonstrate their effectiveness. In responding to the question "what - if" according to indicators, we can assert, that under implementation of the suggested new nutrition norms an adequate social and higher factual effectiveness is achieved.

During the initial period of implementation of the suggested new nutrition norms, there exist the necessary conditions to assert, that also a planned effectiveness is achieved.

Out of the point of view of the granted service "nutrition" at the Ministry of Defense and from the demonstrated here results, a conclusion can be done, that at implementation of the suggested new nutrition norms the highest economic effectiveness is achieved in its clear aspect. This is confirmed by the fact that the values of the factual, of the planned and of the socio-economic effectiveness are close to each other, according to the obtained mark effective or more effective from the valid nutrition norms.

\section{REFERENCES}

Banabakova, V. (2010). Stopanska logistika, Veliko Tarnovo: FABER, 132-141.

Glushkov, P. (2017a). Use of Linear Optimization Model in Defining the New Standards for the Preparation of Food for Servicemen During the Preparation for Participation in Peacekeeping Operations, The 23rd International Conference Knowledge-Based Organization, Vol. XXIII, No. 2, 65-70.

Glushkov, P. (2017b). A Study of Nutrition and the Nutritional Status of Servicemen, Assessed on the Basis of Anthropometric Indicators, The $23^{\text {rd }}$ International Conference Knowledge-Based Organization, Vol. XXIII, No. 2, 298-302.

Nichev, N., \& Glushkov, P. (2016). Economic efficiency of the feeding of servicemen and civilians in NMU "Vasil Levski", under preparation for participation in dispatch operations. Sofia: Publishing complex of the University of National and World Economyreports from the tenth International Scientific Conference on the topic of Logistics in a changing world: Publishing complex of the University of National and World Economy, 329-339.

Nichev, N. (2017a). Offset Policies of the Countries of the European Union, New Knowledge Journal of Science, Vol. 6, No. 1, 121-128.

Nichev, N. (2017b). Perspectives for Use of the Offset Deals, New Knowledge Journal of Science, Vol. 6, No. 1, 129-135.

Terziev, V., \& Nichev, N. (2016). Sravnitelen analizna prilaganeto na ofseta prisdelki sotbranitelni produkti, Yuridicheski sbornik, Vol. 23, 366-373. 